\title{
A Clínica Ampliada e o Trabalho do Psicólogo nos Centros de Referência de Assistência Social
}

\author{
The Extended Clinic and the Work of the Psychologist in Reference Centers for \\ Social Assistance
}

\author{
La Clínica Ampliada y el Trabajo del Psicólogo en los Centros de Referencia de \\ Asistencia Social
}

\author{
Rafael Bianchi Silva ${ }^{1}$ \\ Graziela Lastoria Bonatti \\ Universidade Estadual de Londrina
}

\begin{abstract}
Resumo
O presente trabalho consiste em discutir, a partir de três eixos de análise, o trabalho do psicólogo no Sistema Único de Assistência Social (SUAS) dentro dos Centros de Referência de Assistência Social (CRASs), no que diz respeito ao trabalho social com famílias em sua relação com a clínica ampliada. Inicialmente, realiza-se uma revisão em documentos para parametrizar o trabalho do psicólogo; em seguida, relatam-se pesquisas sobre a prática realizada nos CRASs para analisar as possibilidades de a clínica ampliada ser um instrumento de trabalho para o psicólogo nesse contexto. Conclui-se que, em vista dos objetivos traçados pela política pública de Assistência Social, a clínica ampliada pode se configurar como uma referência importante para o trabalho do psicólogo no CRAS, colaborando para a construção de uma leitura crítica das realidades em que estão inseridos e para o desenvolvimento do protagonismo social junto aos sujeitos e à comunidade em que se acontece sua atuação.
\end{abstract}

Palavras-chave: psicologia, clínica ampliada, CRAS, SUAS

\begin{abstract}
The present work aims to discuss, from three axes of analysis, the work of the psychologist in the Social Assistance Universal System (SUAS) inside the Reference Centers for Social Assistance (CRASs) from social work with families and the relation with extended clinical. Initially, it is realized a review of the public policy documents that seek to parameterize the work of the psychologist; in a second moment, it is reported some researches that describe the psychological practice performed in the CRASs and, finally, an analysis is made about the possibilities of the extended clinic to be a working tool for the psychologist in that context. It is concluded that, in view of the proposed objectives of the public policy of Social Assistance, the expanded clinic can be configured as an important reference for the work of the psychologist at CRAS, collaborating to construct a critical reading of the realities in which they are inserted and for the development of social protagonism together with the subjects and the community in which their action takes place.
\end{abstract}

Keywords: psychology, extended clinical, CRAS, SUAS

\section{Resumen}

El presente trabajo consiste en discutir, a partir de tres ejes de análisis, el trabajo del psicólogo en el Sistema Único de Asistencia Social (SUAS) dentro de los Centros de Referencia de Asistencia Social (CRASs) a partir del trabajo social con familias en su relación con la clínica ampliada . Inicialmente, se realiza una revisión en documentos para parametrizar el trabajo del psicólogo; a continuación, se reportan investigaciones sobre la práctica realizada en los CRASs para analizar las posibilidades de la clínica ampliada para ser un instrumento de trabajo para el psicólogo en ese contexto. Se concluye que, en vista de los objetivos trazados por la política pública de Asistencia Social, la clínica ampliada puede configurarse como una referencia importante para el trabajo del psicólogo en el CRAS, colaborando para la construcción de una lectura crítica de las realidades en que están insertados y para el desarrollo del protagonismo social junto con los sujetos y la comunidad en que se pasa su actuación.

Palabras clave: psicología, clínica ampliada, CRAS, SUAS

\footnotetext{
${ }^{1}$ Endereço de contato: Universidade Estadual de Londrina, Centro de Ciências Biológicas, Departamento de Psicologia Social e Institucional, AC Jardim Bandeirantes, Jardim Portal de Versalhes 1, Londrina, PR, Brasil, CEP 86057970. Telefone: (43) 3371-4487. E-mail: tibx211@yahoo.com.br
} 


\section{Introdução}

O objetivo deste artigo é debater as possibilidades de atuação do psicólogo no âmbito do Centro de Referência da Assistência Social (CRAS) a partir de três frentes: os documentos e as parametrizações oficiais da política, as descrições de práticas realizadas em publicações da área e, por fim, um debate acerca da clínica ampliada, considerada como uma importante perspectiva metodológica de trabalho dentro do SUS e a qual trazemos como mais uma alternativa para a atuação psi no Sistema Único da Assistência Social (SUAS) e, em especial, no Programa de Atenção Integral à Família (PAIF).

Ainda que as políticas sociais tivessem sido estabelecidas no Brasil desde o governo de Getúlio Vargas (1930-1945), a Assistência Social recém-implantada era vista como uma prática vinculada especialmente a instituições de cunho religioso e não necessariamente se configurando como uma política pública. Somente com a Constituição de 1988 ela passou a ser reconhecida como direito em nosso país e como uma forma de garantia de proteção social mais igualitária e universalista a todos que dela necessitassem.

Entretanto o caminho para sua implementação ainda se encontra em construção, visto que, como indicado por Romagnoli (2012), a Assistência Social fundamentava-se no clientelismo, na concessão de benefícios e doações, na ausência de transparência nas ações, bem como na falta de participação da sociedade, sendo pautada, portanto, por ações tradicionalmente clientelistas e assistencialistas.

Na tentativa de alterar esse panorama, em 1993, é criada a Lei Orgânica de Assistência Social (LOAS) e, a partir dela, em consonância com a IV Conferência Nacional de Assistência Social, entra em vigor em 2005 o Sistema Único de Assistência Social (SUAS), o qual passa a ser implantado em todo o território nacional, com o propósito de efetivar uma rede de proteção social e ações pautadas na prevenção, no desenvolvimento global das famílias e das comunidades (Costa \& Cardoso, 2010).

Atualmente, as ações do SUAS encontram-se organizadas em dois níveis de complexidade: a proteção social especial e a proteção social básica, nível no qual se encontram os CRAS. Conforme apontam Silva e Corgozinho (2011), os CRAS destinam-se a fornecer programas socioassistenciais às famílias e aos indivíduos em seu contexto comunitário, visando à orientação e ao convívio sociofamiliar da população em situação de vulnerabilidade. Em 2003, o Plano Nacional de Atendimento Integral à Família passa a ser ofertado obrigatoriamente nos CRASs e organizado de forma a responder à garantia de fortalecimento da convivência familiar e comunitária dos usuários, sendo reformulado anos depois, para sua configuração atual, enquanto PAIF, visando trabalhar aspectos objetivos e subjetivos relacionados à função protetiva da família.

É por meio desse trabalho com usuários e famílias em situação de vulnerabilidade social que o psicólogo começa a exercer um trabalho mais ampliado do que aquele que hegemonicamente encontra-se presente desde a formação inicial. Como apontam Senra e Guzo (2012), a atuação em contextos adversos (como em bairros na periferia das cidades ou em ocupações ou favelas) implica a elaboração de metodologias alternativas às que são comuns e tradicionais no fazer do psicólogo. Ademais, o trabalho a partir de demandas concretas aponta para necessidade de uma revisão das intervenções do profissional da Psicologia, 
levando à necessária transposição dos limites da sala de atendimento para um outro modelo fundamentado na análise das condições sociais e comunitárias em que atuará.

É dentro desse contexto que a problematização das práticas torna-se necessária, visto que a saída para novas possibilidades de ação coloca aos profissionais psi desafios teóricometodológicos, os quais, ao mesmo tempo em que ampliam as formas de compreensão de ser psicólogo, geram angústias quanto aos seus limites. Nosso primeiro eixo de análise aponta para como os documentos oficiais trabalham tais questões.

\section{O que Dizem os Documentos}

Voltadas para técnicos de nível superior que atuam na política de Assistência Social, as "Orientações Técnicas sobre o PAIF" (Brasil, 2012a) foram construídas como forma de servir de embasamento para o trabalho de atendimento e acompanhamento das famílias no CRAS. Sem realizar uma especificação das formas de intervenção próprias para cada categoria profissional que pode atuar no equipamento, o documento afirma que não compete a eles a execução de práticas clínicas (entendidas como ações psicoterapêuticas, psicodiagnósticas, psicopedagógicas), sendo que, caso identificadas tais demandas, essas devem ser encaminhadas para as políticas específicas para seu atendimento (como a saúde e a educação).

Entendemos que tais práticas remetem a uma concepção de clínica tradicional socialmente disseminada, caracterizada por um setting analítico e atendimento realizado comumente de modo individual, que tende à realização de procedimentos diagnósticos e enquadramento dos indivíduos a categorias previamente constituídas. O documento entende que esses procedimentos não cabem no contexto da Política de Assistência Social, visto que acabariam ampliando o processo de segregação e estigmatização de uma ampla parcela da população que, além de encontrar-se sem acesso às práticas hegemonicamente executadas pela Psicologia, têm outros tipos de necessidades que apontam para as dimensões materiais e concretas tanto no que tange às esferas individuais como também familiares e comunitárias.

Em publicação sobre o tema, intitulada "Parâmetros para a atuação de assistentes sociais e psicólogos(as) na Política de Assistência Social" e construída conjuntamente pelos Conselhos Federais de Psicologia e Serviço Social, é pontuado que isso não significa que a prática do psicólogo no CRAS deva eliminar a compreensão da dimensão subjetiva dos fenômenos sociais e coletivos, por meio de diferentes enfoques teóricos e metodológicos que problematizem e proponham ações no âmbito social, de modo a intervir também sobre o sofrimento psíquico.

[...] o sofrimento humano é ético e político, produzido por uma história de desigualdades e injustiças sociais, vivenciado pelo indivíduo, mas que tem origem nas relações construídas socialmente. Assim, o sofrimento não é característico do indivíduo, mas é produto dos processos histórico, político, social e econômico de exclusão, processo que deve ser denunciado nas práticas psicológicas [...]. (Conselho Federal de Psicologia \& Conselho Federal de Serviço Social, 2007, pp. 36-37)

Em outro documento intitulado "Referências Técnicas para atuação do(a) psicólogo(a) no CRAS/SUAS" (Centro de Referência Técnica em Psicologia e Políticas Públicas, 2007), afirmase que cabe ao psicólogo dentro do CRAS a participação nas ações propostas, articulando a 
sua atuação a um plano de trabalho elaborado em conjunto com a equipe interdisciplinar e em nível intersetorial, levando em consideração as investigações sobre as situações no território de abrangência do CRAS e seu público participante: a população em situação de vulnerabilidade social, privação e/ou fragilização de vínculos efetivos relacionais e de pertencimento social.

Temos o compromisso de oferecer serviços de qualidade, diminuir sofrimentos, evitar a cronificação dos quadros de vulnerabilidade, defender o processo democrático e favorecer a emancipação social. Para isso, é importante compreender a demanda e suas condições históricas, culturais, sociais e políticas de produção, a partir do conhecimento das peculiaridades das comunidades e do território (inserção comunitária) e do seu impacto na vida dos sujeitos [...]. (Centro de Referência Técnica em Psicologia e Políticas Públicas, 2007, p. 24)

Isso levaria a uma dupla função, na qual o psicólogo deve utilizar seus conhecimentos para atender e acompanhar as famílias, possibilitando, por meio de sua ação, uma escuta dos aspectos subjetivos envolvidos nas situações de vulnerabilidades vivenciadas pelas famílias (Brasil, 2012a), ao mesmo tempo em que tal ação "[...] tem por finalidade fazer com que os usuários sejam sujeitos de direitos" (Flor \& Goto, 2015, p. 24).

Sendo assim, as atividades do psicólogo no CRAS devem estar voltadas para a atenção e prevenção a situações de risco, objetivando atuar na condição de vulnerabilidade por meio do fortalecimento dos vínculos familiares, comunitários e pelo desenvolvimento de potencialidades e aquisições pessoais e coletivas. Ele deve investir também na mudança da forma de compreender a pobreza e a maneira de atuar sobre ela, a fim de que, por meio dos vínculos estabelecidos no atendimento, por meio de um conjunto de ações, possa potencializar o rompimento do ciclo de pobreza, a independência em relação aos benefícios oferecidos e a promoção da autonomia.

Segundo as "Orientações Técnicas..." (Brasil, 2012a), isso aponta para que as ações junto às famílias, além de desenvolver o entendimento das formas com que são materializadas as situações de vulnerabilidade, necessitam problematizar tais condições de modo a gerar o enfrentamento da vulnerabilidade com foco na quebra de sua repetição em nível intergeracional.

O mesmo documento indicado acima descreve como formas de atendimento que o psicólogo - enquanto trabalhador da política - pode desenvolver as ações como acolhida, entrevistas (tanto domiciliares como no CRAS), orientações, referenciamento e contrarreferenciamento, visitas domiciliares, articulações institucionais (dentro e fora do território de abrangência do CRAS), proteção proativa, atividades socioeducativas e de convívio, com o intuito de facilitar processos de identificação, construção, atualização de potenciais pessoais, grupais, comunitários, de modo a fortalecer atividades e positividades já existentes nas interações dos moradores.

Enquanto objetivo de tais procedimentos, o trabalho do psicólogo visa à formação de espaços de interação que envolvam vivências, leitura crítica da realidade, com a finalidade de que as pessoas reconheçam-se e se movimentem na condição de coconstrutoras de si e dos seus contextos social, comunitário e familiar (Centro de Referência Técnica em Psicologia e Políticas Públicas, 2007). Para tanto, torna-se necessária a realização de um processo 
reflexivo que tenha como ponto de partida situações reais e concretas, buscando a construção de uma relação dialógica que problematize as condições de existência.

Esse diálogo busca construir o caráter coletivo implicado nessas situações e, por isso, o processo reflexivo pode ser caracterizado como a experiência na qual as pessoas mudam sua maneira de compreender o mundo e as relações humanas. Através dele podese enriquecer a maneira como encaram a si mesmas, os outros e a realidade, ao mesmo tempo em que se envolvem na conquista de novas forças e de novos instrumentos para transformar a realidade vivenciada. Assim, torna-se possível: a) incrementar as discussões sobre as questões cujas soluções estão fora do alcance das famílias individualmente e, b) possibilitar a organização coletiva. (Brasil, 2016)

Isso implica também a compreensão e o acompanhamento por parte dos profissionais psi dos movimentos de construção subjetiva de pessoas, grupos e famílias, bem como implica o ato de colaborar com a construção de processos de mediação, organização e mobilização social que levem à efetivação de direitos sociais e melhoria das condições de vida dos participantes do CRAS.

Todos esses passos serão de enfrentamento, de desnaturalização da violação de direitos, de superação das contradições sociais, se cada vez mais, e mais profundamente, nós estivermos implicados na sua execução. Diretamente, na medida em que é necessário propor ações de monitoramento, definição de indicadores de funcionamento e de resultado que orientem nossas atividades. Indiretamente, pois o sujeito, atendido plenamente pelo profissional implicado em seu processo de cidadania, desenvolve, pela própria experiência, a autonomia e o empoderamento, para fazer valer seus direitos. (Centro de Referência Técnica em Psicologia e Políticas Públicas, 2007, p. 18)

Os documentos apontam que os profissionais devem pautar suas ações tendo por fundamento uma perspectiva teórica, técnica e ética. Isso nos leva à tarefa, por parte dos profissionais da Assistência Social, de acompanhar as resoluções que norteiam o exercício profissional, construindo novos dispositivos que rompam com o privativo da clínica ao mesmo tempo que garantam a especificidade da formação em Psicologia, que implica levar em conta a valorização do outro enquanto fundamento da prática, além de intervenção e escuta comprometida com o processo de superação e de promoção da pessoa em sua integralidade.

Conforme foi possível observar nessa breve passagem pelos documentos que fazem referência direta ou indireta ao trabalho do psicólogo na política de Assistência Social, há uma tentativa de ampliação do modo como é materializado o serviço da Psicologia nesse contexto. Considerando que o trabalho no âmbito da Política Nacional de Assistência Social é algo recente e que a formação para atuação em contextos que ultrapassem a clínica tradicional ainda permanece à margem na formação inicial, alguns desafios vêm sendo suscitados por esses profissionais.

Muitos psicólogos relatam, por meio de suas experiências, ter dificuldades em reconhecer quais são suas demandas e possibilidades de atuação na referida política. Além disso, a inserção no contexto do CRAS tem provocado muitos questionamentos acerca do que é específico da Psicologia e de como atuar para modificar as condições materiais de existência das famílias usuárias do serviço. Nosso próximo eixo de análise avançará nessa direção. 


\section{O que Dizem os Psicólogos que Atuam nos CRASs}

Ainda que exista uma série de documentos que buscam apontar um caminho para a atuação do profissional de Psicologia, torna-se necessário compreender como as práticas dos psicólogos que atuam na política de Assistência Social vêm se construindo no cotidiano, de modo a mapear as suas dificuldades e questionamentos. Nesse sentido, o trabalho do psicólogo no contexto social das Políticas Públicas tem suscitado diversas discussões e fomentado uma série de materiais de pesquisa que vêm sendo produzidos com o objetivo de levantar como esses profissionais concebem sua atuação, quais seus questionamentos, dificuldades e dilemas enfrentados durante seu exercício profissional.

Em pesquisa realizada na região metropolitana de Natal, RN, Oliveira, Dantas, Solon e Amorim (2011) levantaram dados sobre as atividades mais exercidas pelos psicólogos que atuavam nos CRASs. Entre elas, destacaram-se atividades socioeducativas (atividades de grupos, palestras, dinâmicas, rodas de conversa, entre outras); acompanhamentos psicossociais (envolvendo acolhimentos das famílias beneficiárias do Programa Bolsa Família); planejamento de ações; registro de atividades a fim de fornecer um quadro geral do que vem acontecendo no serviço e possibilitar um monitoramento; e, por fim, atividades clínicas, as quais foram justificadas pela maior identificação dos profissionais psi com essa área e pela insuficiência de profissionais e instituições que podem acolher essas demandas.

Em outros dois estudos também realizados no Rio Grande do Norte, fica clara a referência a trabalhos de cunho socioeducativo como prática recorrente na atuação do psicólogo, sendo identificada como importante para a articulação com as redes intersetoriais e socioassistenciais dos profissionais. Oliveira, Oliveira, Nascimento, Araújo, Coelho-Lima e Amorim (2014) descrevem o envolvimento de profissionais psi na realização, por exemplo, de grupos geracionais, de convivência, terapêuticos; oficinas, palestras, capacitação de merendeiras, reuniões etc. Por sua vez, em pesquisa recente, Oliveira, Nascimento, Araújo e Paiva (2016) afirmam que existe um rol de ações consideradas primordiais e que, embora importantes como o acompanhamento familiar, visitas por denúncia, mapeamentos das redes e das potencialidades da comunidade -, se destacaram como sendo pouco executadas. Esse dado é corroborado com aqueles destacados por Leão, Oliveira e Carvalho (2014), os quais abordam que também as atividades de vigilância e a territorialização são praticamente inexistentes na conduta dos profissionais psi.

Outro estudo descrito por Cruz (2009) abrangeu 38 municípios de Sergipe e apontou dados evidenciando que os psicólogos nessa área desenvolviam uma gama variada de atividades (como a participação em comissões relacionadas às políticas da assistência, participação de reuniões com a equipe técnica, organização e participação de atividades recreativas, realização de grupos de prevenção e orientação etc.). Porém também ficou claro que, entre as atividades mais desenvolvidas nos CRAS investigados, estavam aquelas voltadas para ações psicoterapêuticas (individual, em grupo, familiar e com casais), sendo poucas realizadas conjuntamente com as equipes técnicas, o que fragilizava a discussão dos casos apresentados.

Esse elemento está vinculado a uma série de fatores. Araújo (2010), por exemplo, traz em seu trabalho um relato de alguns profissionais de determinados CRAS de São Paulo. Um dos psicólogos entrevistados afirma que, diferentemente dos assistentes sociais que trabalham com recursos concretos (como a cesta básica, Bolsa Família etc.), a atuação da Psicologia 
encontra-se vinculada à atenção a elementos que outros profissionais não se atentam, como o campo emocional e a autoestima dos sujeitos, trabalhando com questões que se encontram mais latentes nos usuários. Ele pontua que, mesmo considerando tal dimensão, não sabe exatamente o que faz no espaço do CRAS.

Outro ponto também importante é a menção sobre o trabalho em grupo como modalidade privilegiada para o trabalho do psicólogo, sendo este profissional visto como o mais capaz de coordenar tais atividades. Embora seja dito que o profissional psi é mais informado e tem mais habilidades para conduzir grupos, vemos que tal profissional se apresenta com pouco suporte e temeroso na realização dessas atividades. Flor e Goto (2015) realizaram uma pesquisa com diversos psicólogos dos CRAS no município de Uberlândia/Minas Gerais, a fim de compreender a atuação desses profissionais nesse contexto. Ainda que tal modalidade de trabalho seja privilegiada pela instituição, ela acaba por se materializar no formato de palestras. As autoras obtiveram relatos de vários participantes que indicam dificuldades em trabaIhar para formulação e desenvolvimento de atividades grupais, o que inclui estabelecimento de temas para grupos ou mesmo conhecimento sobre o funcionamento e a dinâmica desses.

A mesma pesquisa também indicou dificuldade quanto à dimensão terapêutica da ação do psicólogo. Enquanto alguns profissionais apontaram o caráter terapêutico/preventivo - a partir de um olhar sobre a relação indivíduo-família e o contexto em que estão inseridos -, outros participantes reconheceram e descreveram que o trabalho desempenhado dentro do CRAS não é de caráter psicoterapêutico, ainda que suas análises indiquem elementos contraditórios, como a realização de orientações breves (que implicam levantamento de dados, investigação e encaminhamento, se for o caso) ou ainda, sem muita clareza, diferenciar psicoterapia, terapia e terapêutica.

Apesar de muitos psicólogos reconhecerem que no CRAS não cabem ações psicoterapêuticas, vemos que tal prática é comum. As pesquisas de Oliveira et al. (2011) demonstram que, apesar de estar acontecendo o desenvolvimento de outras práticas psi distintas das tradicionais nos CRAS, observa-se a predominância do acompanhamento especializado e a atividade clínica tradicional. Nessa mesma direção, a pesquisa de Macêdo, Alberto, Santos, Souza e Oliveira (2015) realizada com psicólogos do Nordeste demonstra que esses profissionais realizavam nos CRASs, predominantemente, escuta psicológica, atendimento clínico, aconselhamento ou terapia psicológica. Mesmo tendo conhecimento de que não era a forma de atuação indicada pelos documentos da política, realizavam essas ações por causa da grande demanda de atendimento e pela dificuldade de encaminhar os usuários para os outros serviços da rede (o CAPS, por exemplo).

Outra questão levantada é a de que vários profissionais psi relatam deficits em suas formações. Tanto nos relatos obtidos por Flor e Goto (2015) quanto Macêdo et al. (2015) são encontradas falas que indicam a ausência de contato com a política pública do SUAS na formação acadêmica inicial, além de sugestões de que os cursos superiores deveriam se apropriar mais sobre o CRAS. Este último artigo revela, por meio das entrevistas feitas, que os psicólogos não se consideram preparados para atuar no CRAS, visto que não tiveram uma boa formação, sendo esta voltada para uma perspectiva individualizante, com um viés clínico e disciplinas puramente teóricas, o que fez com que eles só viessem a conhecer o equipamento quando passaram a trabalhar em tal política. 
Além disso, somada à queixa de despreparo quanto à atuação com um grande número de famílias, observa-se dificuldade em lidar com questões mais amplas que atravessam o cotidiano do CRAS e remetem à dimensão macrossocial, como o fenômeno da violência, dependência química, questões de gênero, pontos não discutidos ou discutidos de modo breve e superficial durante a formação acadêmica.

Esses dados corroboram as informações coletadas por Costa e Alberto (2017) com psicólogos e assistentes sociais do município de João Pessoa. Os psicólogos que atuavam no CRAS apresentavam formação e especialização voltadas para o viés clínico e distante das políticas sociais. Ademais, a pesquisa também mostrou que não havia estagiários de Psicologia no serviço, o que permite refletir que o trabalho vinculado à proteção social tem uma relação mais frágil com esse campo em relação a outras formações (como o Serviço Social), além de retroalimentar a distância entre curso universitário e a política pública de Assistência Social.

A partir dos dados apresentados nos estudos indicados, foi possível abordar a ampla possibilidade de atuação psicológica no CRAS e identificar, em especial, por meio dos relatos dos psicólogos, suas dificuldades, principalmente na fundamentação de suas práticas. Como alternativa, o terceiro eixo proposto em nossas reflexões diz respeito à clínica ampliada como perspectiva teórico-metodológica ao trabalho no âmbito do CRAS.

\section{Clínica Ampliada como Perspectiva para o Psicólogo que Atua no CRAS}

A clínica social é implantada no país ao fim dos anos 1970, por meio de uma dupla ação de movimentos populares (prática) e universidade (teórica) que acabaram por promover programas que incorporaram de forma gradativa a Psicologia na comunidade. Como bem descreve Romagnoli (2006), esse novo momento político de nosso país (que culminou com a abertura política nos anos 1980) confronta a ideia de uma prática clínica voltada apenas para as classes média e alta. Assim, ocorre o desenvolvimento de uma nova clínica, que se vê implicada com a construção de novas formas de intervenção.

Paralelo a esse processo de formação de uma clínica mais includente, ocorre a construção de um olhar para a relação com os sujeitos, preocupada em ampliar o atendimento clínico em diferentes contextos e, para além, a relação saúde-doença. Entre os precursores de tal perspectiva chamada de "clínica ampliada" ou "clínica do sujeito", temos o italiano Franco Basaglia, o qual, segundo Campos (2000), nos trouxe uma visão clínica tomada como um instrumento para reconhecer o paciente como uma pessoa com direitos e ao mesmo tempo como protagonista capaz de fazer valer seus próprios direitos. Como forma de explicar os pressupostos dessa perspectiva, Rotielli (1990, p. 3) afirma:

A produção da vida e a reprodução social que são o objetivo e a prática da "instituição inventada" devem evitar as estreitas vias do olhar clínico, assim como da investigação psicológica e da simples compreensão fenomenológica, e fazer-se tecido, engenharia de reconstrução de sentido, de produção de valor, tempo, responsabilizar-se, de identificação de situações de sofrimento e de opressão, reingressar no corpo social, consumo e produção, trocas, novos papéis, outros modos materiais de ser para o outro, aos olhos do outro.

Por meio dessa visão, Basaglia propôs um olhar clínico voltado para existência concreta dos sujeitos, retirando a ênfase do processo de cura da pessoa e colocando em primeiro 
lugar o sujeito e todos seus aspectos subjetivos e sociais. Conforme aborda Amarante (2009), Basaglia deslocou o problema do homem não mais como entidade abstrata, definível segundo um sistema de categorias fechadas, mas sim como sujeito-objeto de um sofrimento social. Partindo disso, a principal questão da proposta foi a mudança de entendimento da doença, sendo esta tomada em sua relação com o campo social.

Diante dessas considerações, entendemos que o conceito de clínica ampliada colocou ao psicólogo (clínico) uma ampla gama de preocupações que acabou por contrapor a prática à atuação em consultórios privados que possuíam (e ainda possuem) ênfase hegemônica na condução de psicoterapia individual e avaliações psicodiagnósticas. Além disso, por se pautar em ações sociais amplas, esse conceito surgiu como um meio de fornecer possibilidades de uma ampliação teórica também no que diz respeito à construção da subjetividade e sua relação com o mundo vivido e existencial da população atendida.

... A ampliação de suas bases conceituais, avançando para além da alopatia, da racionalidade clínica da biomedicina; ampliar incluindo práticas complementares; ampliar para além do biológico, incluindo as dimensões social e subjetiva (afinal, a produção de saúde se dá para além e aquém da experiência material do corpo); ampliar para ação interdisciplinar, com aposta no trabalho em equipe. Construir uma relação clínica que seja uma experiência de troca entre sujeitos, não de alguém que sabe e alguém que não sabe; uma clínica que não seja encontro episódico, mas a construção de vínculo e confiança no tempo, permitindo a contração de responsabilidades na rede de saúde; enfim, ampliar a clínica significa reconstruir relações de poder na equipe e com os usuários e sua rede sócio-familiar, ampliando processos de troca e de responsabilização mútua .... (Brasil, 2010)

Nesse contexto, a discussão em torno da subjetividade aparece com o objetivo de não culpabilizar o indivíduo, mas afirmá-lo como historicamente construído. Dessa maneira, percebemos que o fornecimento de apoio social, como na proposta da clínica ampliada, pode contribuir para a mobilização das subjetividades dos indivíduos, favorecendo condições para suscitar potencialidades, melhor qualidade de vida e construção de novos modos de existência.

Assim, a subjetividade não implica uma posse, mas uma produção incessante que possui nos encontros que vivemos com o outro um espaço privilegiado. Nesse sentido, "[...] a subjetividade não é passível de totalização ou de centralização do indivíduo" (Guatarri \& Rolnik, 1996 citado por Mansano, 2009, p. 111), o que confere à clínica um fazer-outro que objetiva a construção de diferentes modos de ser que ultrapassam a dimensão presente, sendo, portanto, criação, invenção e acima de tudo produção de si.

Conforme Hafner, Moraes, Marvulo, Braccialli, Carvalho e Gomes (2010), a clínica ampliada possibilita que outros aspectos do sujeito, que não apenas o biológico, possam ser compreendidos e trabalhados pelos profissionais e visa à ampliação do grau de autonomia do usuário, da família e da comunidade. Ademais, conforme aborda Campos, Figueiredo, Pereira e Pereira de Castro (2014), baseia-se na escuta e reconhece o saber, o desejo e o interesse das pessoas, questionando-as sobre os sentidos daquilo que estão vivendo, configurando-se como uma prática menos prescritiva e mais negociada.

Segundo Murta e Marinho (2009), a prática da clínica ampliada se torna ampla em diversos sentidos, no que diz respeito ao espaço físico (da sala privada a instituições diversas), à 
população a ser atendida (das classes sociais médias e altas às de baixa renda), aos agentes de execução do trabalho (da atuação exclusiva do psicólogo à conduzida por profissionais com diversos saberes) e em relação ao nível de prevenção (do relacionado à reabilitação e tratamento à prevenção e promoção de saúde).

Mas de que forma a clínica ampliada pode se relacionar com o trabalho no âmbito do CRAS? Por meio das considerações de Basaglia sobre a clínica ampliada, encontramos um caminho que permite articular alguns pressupostos do SUAS com essa clínica voltada para o sujeito. Dentro das propostas do autor articuladas ao campo das Políticas Públicas, temos a valorização das demandas concretas dos usuários. Ele afirma que "o importante para a pessoa é ter o que comer, ter dinheiro, ter uma cama para dormir" (Basaglia, 1979, p. 31), ou seja, as necessidades sociais do usuário (as quais foram socialmente e historicamente produzidas pelo jogo social) são importantes e devem ser consideradas em sua singularidade.

Esse pressuposto também é visto no SUAS. Os usuários do PAIF também devem ter suas demandas concretas atendidas, visto que as pessoas inseridas no serviço vivenciam situações de vulnerabilidade que decorrem de fatores como pobreza, privação, fragilização de vínculos afetivos, entre outros. Outra pontuação colocada por Basaglia é a importância de incluir dentro da análise material dos sujeitos uma avaliação das dimensões sociais e subjetivas dos usuários, de modo a não olhar apenas a situação orgânica. É necessário realizar um diagnóstico que envolva as pessoas em sua totalidade.

O SUAS também permite essa mudança de foco, ao demonstrar que os profissionais não devem olhar apenas para a questão da pobreza dos usuários, mas para todos os aspectos sociais e subjetivos que os envolvem, como forma de acessar os atributos sociais necessários para potencializar o exercício do protagonismo e da autonomia das famílias e de seus membros. Para além da dimensão individual, enquanto atividade proposta ao trabalhador social, inclui-se a realização de um diagnóstico também do território, conhecendo as possibilidades e potencialidades das famílias para assim mapear

... necessidades e características similares, de forma a efetivar seu acompanhamento, tornando-o um processo de compartilhamento de experiências entre os participantes, de reflexão sobre a realidade, de acesso à informação sobre direitos, de apoio à família em sua função protetiva e de construção de projetos de vida que possibilitem ampliação dos direitos sociais. (Brasil, 2012b, p. 64)

Um terceiro item apontado pelo italiano é a importância da ação política dos profissionais na valorização da emancipação do sujeito, de forma a permitir aos usuários a saída da condição de passividade para o questionamento da realidade e a tomada de uma postura ativa. As assembleias gerais, os grupos-apartamentos, as empresas sociais e todo o sistema de redes criado em Trieste por Basaglia e seus colaboradores visavam a essa autonomia e à possibilidade de uma transformação social dos indivíduos.

No SUAS, a questão do empoderamento dos sujeitos também é colocada junto do objetivo da aquisição dos usuários de uma consciência coletiva de dependência social, com o objetivo de permitir que os membros participem de espaços de decisões e consciência de seus direitos. Assim, "o trabalho social com famílias deve garantir apoio e proteção às famílias, promovendo maiores graus de autonomia e empoderamento, negando uma ação 
moralizadora ou modeladora dos modos de vida e das crenças dos grupos familiares" (Brasil, 2012a, p. 20).

Isso posto, vemos algumas articulações da proposta da clínica ampliada com o trabaIho no PAIF, o qual tem como principal objetivo o trabalho no campo das subjetividades, sem negar a importância das situações objetivas de vulnerabilidade que atingem as famílias. Assim, entende-se que se trata de um trabalho em que é construído um espaço relacional a partir do qual o trabalho social pode ser concretizado e, por meio dessa atuação, é possível o fortalecimento dos vínculos familiares e comunitários, assim como há possibilidade de acesso a transformações individuais e coletivas visando à ultrapassagem da condição de vulnerabilidade.

\section{Considerações Finais}

Por muito tempo a Política Nacional de Assistência Social se caracterizou por posturas paternalistas e assistencialistas. Somente com a criação do SUAS foi possível criar e colocar em prática uma nova concepção de Assistência Social, de modo a permitir ações que potencializem a população para um entendimento acerca de suas condições, a fim de configurar aos grupos atendidos um desenvolvimento mais amplo e global. É por meio desse novo panorama que o PAIF é implantado como oferta obrigatória nos CRAS, com o objetivo de possibilitar aos usuários o acesso a programas e benefícios socioassistenciais, além da participação em atividades que tenham por objetivo o fortalecimento de vínculos familiares e comunitários e, em especial, a tomada de posição enquanto protagonista.

Assim, o psicólogo é inserido nesse contexto tendo como um dos principais objetivos o trabalho no campo das subjetividades dos usuários, de modo a suscitar a construção de espaços que potencializem aos usuários uma leitura crítica das realidades em que estão colocados. Ao mesmo tempo em que são realizadas tais proposições e reconhece-se um lugar para a Psicologia, os documentos que parametrizam a política também restringem a intervenção psicológica em suas formas mais tradicionais, colocando ao profissional psi a tarefa necessária de se (re)inventar.

Nesse sentido, entendemos que a clínica ampliada oferece possibilidades de uma outra clínica, que se configura como uma prática alinhada com os objetivos propostos pelo SUAS, o que também pode possibilitar um novo olhar sobre os serviços ofertados, as questões sobre as quais eles atuam e as potencialidades do saber e das práticas psicológicas em tal contexto.

Apesar de reconhecer o papel de agentes de transformação, o que encontramos, nas diferentes pesquisas publicadas e aqui citadas, foi a dificuldade do profissional psi em avançar em suas práticas para além da dimensão individual, reconhecendo as demandas dos usuários a partir da incidência de questões concretas e macrossociais materializadas na vivência em determinado território, processo esse que pode ser mais bem apropriado com uma aproximação das premissas e problemáticas levantadas pela clínica ampliada.

Pelo fato de o trabalho do psicólogo no âmbito do SUAS se configurar como algo relativamente recente, encontramos também dificuldades no que tange à formação acadêmica inicial que se mostra precária quanto à falta de acesso a informações sobre as políticas públicas, o que não garante respaldo suficiente para a atuação no âmbito do CRAS. Como 
resultado desse processo, mesmo com o aumento considerável de produções que discutem a atuação do psicólogo no SUAS, uma ampla gama de profissionais que vão atuar nesse contexto não tem conhecimento de tais referências, e isso gera impactos para a consolidação do trabalho da Psicologia na referida política.

Apontadas essas dificuldades, é importante pensar em um instrumento que auxilie o psicólogo em suas atividades exercidas com as famílias do PAIF. Observamos que as premissas da clínica ampliada a colocam como alternativa possível, a partir da qual o psicólogo pode repensar e ressignificar suas ações no âmbito do CRAS. Entendemos que a clínica ampliada, em sua especificidade, permite ao psicólogo uma perspectiva crítica das questões sociais, culturais e políticas dos usuários, auxiliando-o durante o trabalho com as famílias na exploração dos significados presentes nas ações dos sujeitos, de modo a apreender o sentido que leva a determinadas direções, relacionamentos, conflitos e decisões.

Nesse sentido, compreendemos que a disseminação e a adoção das premissas encontradas na clínica ampliada, enquanto perspectiva de trabalho pelos psicólogos atuantes no CRAS, geram possibilidade de esses profissionais oferecerem aos usuários uma escuta clínica qualificada das questões vivenciadas no cotidiano, com uma visão diferenciada da dimensão subjetiva, possibilitando a eles uma construção de alianças, invenção de espaços de transformação e uma ampliação da compreensão de vida, de modo que possam encontrar formas de enfrentamento das suas dificuldades.

Dessa forma, entendemos que a clínica ampliada não fica restrita apenas ao âmbito das políticas de saúde, configurando-se como uma alternativa teórico-metodológica-ético-política para que o psicólogo inserido no contexto do CRAS atue, a partir das questões propostas pelo PAIF, em um trabalho no campo das subjetividades, potencializando o protagonismo dos usuários, de forma a construir um olhar crítico deles sobre a realidade em que estão inseridos e os meios para ressignificar suas vidas e criar novas possibilidades de ação em seu mundo vivido.

\section{Referências}

Amarante, P. (2009). Reforma psiquiátrica e epistemologia. Cadernos Brasileiros de Saúde Mental, 1(1), 1-7.

Araújo, F. I. C. D. (2010). "... Mas a gente não sabe que roupa dever usar": Um estudo sobre a prática do psicólogo no Centro de Referência de Assistência Social (Dissertação de Mestrado, Programa de Pós-Graduação em Psicologia Social, Pontifícia Universidade Católica do Estado de São Paulo - PUC-SP, São Paulo).

Basaglia, F. (1979). A psiquiatria alternativa: Contra o pessimismo da razão, o otimismo da prática: Conferências no Brasil. São Paulo: Brasil Debates.

Brasil. Ministério da Saúde. (2010). Cadernos Humaniza SUS. Brasília. Disponível em http:// bvsms.saude.gov.br/bvs/publicacoes/cadernos_humanizaSUS.pdf.

Brasil. Ministério do Desenvolvimento Social e Combate à Fome. (2012a). Orientações técnicas sobre o PAIF: O serviço de proteção e atendimento integral à família, segundo a tipificação nacional de serviços socioassistenciais (Vol. 1). Brasília: MDS. Disponível em http://agendaprimeirainfancia.org.br/arquivos/Orientacoes_PAIF_1.pdf. 
Brasil. Ministério do Desenvolvimento Social e Combate à Fome (2012b). Orientações técnicas sobre o PAIF: O serviço de proteção e atendimento integral à família, segundo a tipificação nacional de serviços socioassistenciais (Vol. 2). Brasília: MDS. Disponível em http://agendaprimeirainfancia.org.br/arquivos/Orientacoes_PAIF_2.pdf.

Brasil. Ministério do Desenvolvimento Social e Combate à Fome (2016). Fundamentos ético-políticos e rumos teórico-metodológicos para fortalecer o Trabalho Social com Famílias na Política Nacional de Assistência Social. Brasília: MDS. Disponível em http://www.mds.gov.br/webarquivos/publicacao/assistencia_social/Cadernos/ TrabalhoSocialcomFamilias.pdf.

Campos, G. W. S. (2000). Saúde pública e saúde coletiva: Campo e núcleo de saberes e práticas. Ciência \& Saúde Coletiva, 5(2), 219-230.

Campos, W. S. G., Figueiredo, D. M., Pereira Jr., N., \& Pereira de Castro, C. (2014). A aplicação da metodologia Paideia no apoio institucional, no apoio matricial e na clínica ampliada. Interface-Comunicação, Saúde e Educação, 18(1), 983-995.

Centro de Referência Técnica em Psicologia e Políticas Públicas (2007). Referências técnicas para atuação do(a) psicólogo(a) no CRAS/SUAS. Brasília: CREPOP. Disponível em http:// site.cfp.org.br/wp-content/uploads/2007/08/cartilha_crepop_cras_suas.pdf.

Conselho Federal de Psicologia, \& Conselho Federal de Serviço Social. (2007). Parâmetros para a atuação de assistentes sociais e psicólogos(as) na Política de Assistência Social. Brasília: CFESS: CFP. Disponível em http://www.cfess.org.br/arquivos/ CartilhaFinalCFESSCFPset2007.pdf.

Costa, R. R., \& Alberto, M. F. P. (2017). Discursos sobre família e a formação para o trabalho social no Centro de Referência da Assistência Social. Revista Pesquisas e Práticas Psicossociais, 12(1), 193-208.

Costa, A. F. \& Cardoso, C. L. (2010). Inserção do psicólogo em Centros de Referência de Assistência Social- CRAS. Revista Interinstitucional de Psicologia, 3(2), 223-229.

Cruz, J. M. O. (2009). Práticas psicológicas em Centro de Referência da Assistência Social. Psicologia em Foco, 2(1), 11-27.

Flor, T. C., \& Goto, T. A. (2015). Atuação do psicólogo no CRAS: Uma análise fenomenológicoempírica. Revista da Abordagem Gestáltica, 21(1), 22-34.

Hafner, M. D. L. M. B., Moraes, M. A. A. D., Marvulo, M. M. L., Braccialli, L. A. D., Carvalho, M. H. R. D., \& Gomes, R. (2010). The medical education and the extended general practice: Results of a Brazilian experiment. Ciência \& Saúde Coletiva, 15, 1715-1724.

Leão, S. M., Oliveira, I. M. F. F., \& Carvalho, D. B. (2014). O psicólogo no campo do bem-estar social: Atuação junto às famílias e indivíduos em situação de vulnerabilidade e risco social no Centro de Referência de Assistência Social (CRAS). Estudos e Pesquisas em Psicologia, 14(1), 264-289.

Macêdo, O. J. V., Alberto, M. F. P., Santos, D. P., Souza, G. P., \& Oliveira, V. S. (2015). Ações do profissional de psicologia no centro de referência da assistência social. Psicologia: Ciência e Profissão, 35(3), 809-823.

Mansano, S. R. V. (2009). Sujeito, subjetividade e modos de subjetivação na contemporaneidade. Revista de Psicologia da UNESP, 8(2), 110-117. 
Murta, S. G., \& Marinho, T. P. C. (2009). A clínica ampliada e as políticas de assistência social: Uma experiência com adolescentes no Programa de Atenção Integral à Família. Revista Eletrônica de Psicologia e Políticas Públicas, 1(1), 58-72.

Oliveira, I. F., Dantas, C. M. B., Solon, A. F. A. C., \& Amorim, K. M. O. (2011) A prática psicológica na proteção básica do SUAS. Psicologia \& Saúde, 23, 140-149.

Oliveira, I. F., Oliveira, N. L. A., Nascimento, M. N. C., Araújo, R. L., Coelho-Lima, F., \& Amorim, K. M. O. (2014). Atuação dos psicólogos nos CRAS do interior do RN. Psicologia \& Sociedade, 26(n. esp. 2), 103-112.

Oliveira, N., Nascimento, N. M. C., Araújo, R. L., \& Paiva, I. L. (2016). Relato de experiência: A atuação do psicólogo no CRAS e sua contribuição para o fortalecimento dos direitos sociais. Psicologia em Revista, 22(1), 31-45.

Romagnoli, R.C. (2006). Algumas considerações sobre a clínica social. Revista do Departamento de Psicologia - UFF, 18(2), 47-56.

Romagnoli, R. C. (2012). O SUAS e a formação em psicologia: territórios em análise. Revista ECOS - Estudos Contemporâneos da Subjetividade, 2(1), 120-132.

Rotelli, F. (1990). A instituição inventada. Desinstitucionalização, 2, 89-99

Senra, C. M. G.; Guzo, R. S. L. (2012). Assistência social e psicologia: Sobre as tensões e conflitos do psicólogo no cotidiano do serviço público. Psicologia \& Sociedade, 24(2), 293-299.

Silva, J. V., \& Corgozinho, J. P. (2011). Atuação do psicólogo, SUAS/CRAS e psicologia social comunitária: Possíveis articulações. Psicologia \& Sociedade, 23(n. esp.), 12-21.

Recebido em: 24/12/2018

Última Revisão: 24/04/2019

Aceite Final: 08/05/2019

\section{Sobre os autores:}

Rafael Bianchi Silva - Pós-Doutor em Psicologia pela Universidade Estadual de Maringá (UEM). Doutor em Educação (Unesp/Marília). Docente do Departamento de Psicologia Social e Institucional e do Programa de Pós-Graduação da Universidade Estadual de Londrina (UEL), Londrina, Brasil. E-mail: tibx211@yahoo.com.br, Orcid: http://orcid.org/0000-0002-1170-7920

Graziela Lastoria Bonatti - Psicóloga formada pela Universidade Estadual de Londrina (UEL). Fez residência em Psicologia Pediátrica no Hospital das Clínicas de Ribeirão Preto (HCRP-USP). Bolsista Iniciação Científica PIBIC-CNPq (2016-2017). E-mail: grabonatti1580@gmail.com, Orcid: http://orcid.org/0000-0002-6000-0542 